\title{
Study on the wall optimization of solar greenhouse based on temperature field experiment and CFD simulation
}

\author{
Yang Yu, Xiao Xu, Wenxiu Hao* \\ Hebei Agricultural University, Baoding 071001, China
}

Corresponding Author Email: hwxansys@126.com

https://doi.org/10.18280/ijht.360310

Received: 25 December 2017

Accepted: 15 June 2018

\section{Keywords: \\ greenhouse, temperature field, \\ experiment, CFD, wall optimization}

\begin{abstract}
In light of the great soil wall sizes of solar green houses and the low land utilization rate of solar greenhouses in China, this paper carries out a temperature field experiment in a solar greenhouse in order to understand the distribution of temperature field in the greenhouses in Central Hebei region. On the basis of the experiment, this paper establishes a numerical model of the temperature field in the solar greenhouse using the CFD software, and optimizes the wall structure of the greenhouse by the numerical simulation of different heights and thicknesses. The results can provide technical reference for the construction of new-type energy-saving solar greenhouses.
\end{abstract}

\section{INTRODUCTION}

As a unique type of greenhouse in China, the solar greenhouse has the advantages of low cost, simple construction process, good thermal insulation performance and high production efficiency, so it is widely used in some underdeveloped areas. Unfortunately, in most cases, the builders construct these greenhouses based on experience. They blindly pursue the effect of insulation, which results in excessively thick and tall back walls and serious waste of land resources and further leads to lower production efficiency. In order to simplify the greenhouse walls, researchers have conducted a great number of studies on the heat storage characteristics and size of the the solar greenhouse wall. Li et al. [1] proposed the method to determine the thickness of the thermal storage layer of the greenhouse wall; Peng et al. [2] believed that there exists an "effective heat accumulation layer" in the wall; He Fen et al. [3] believed that the wall surface temperature does not vary greatly in the vertical direction, but fluctuates much in the thickness direction; $\mathrm{Xu}$ et al. [4] proposed that the $370 \mathrm{~mm}$ thick brick wall directly coated with polystyrene insulation boards has a good thermal insulation effect; Yang et al. [5] suggested that the optimal thickness of the wall is $1.0 \mathrm{~m}$ in Yangling, Shaanxi, $1.3 \mathrm{~m}$ in Baiyin, Gansu, $1.5 \mathrm{~m}$ in Yinchuan, Ningxia and $1.4 \mathrm{~m}$ in Tacheng, Xinjiang; Tong [6] simulated the change of temperature in a temperature room by software, and the results were consistent with the field measured values; Zhang et al. [7] established a sunken greenhouse cob wall model and carried out the threedimensional unsteady simulation, and the results accorded with the reality.

At present, solar greenhouses with soil walls are widely used in Central Hebei region, but wall sizes are quite irrational, and few research has been done on the rational thickness of such walls in Central Hebei region. This paper uses the Ansys CFD software to simulate the temperature field of the greenhouse and in this way optimize the wall thickness. The optimization results are of great significance to the actual construction of solar greenhouses.

\section{TEMPERATURE FIELD EXPERIMENT}

\subsection{Experimental equipment layout}

The experiment was conducted in a sunken solar greenhouse at a vegetable base in Wangdu County $\left(115.12^{\circ} \mathrm{e}, 38.72^{\circ} \mathrm{n}\right)$ of Hebei Province, with an excavation depth of $0.9 \mathrm{~m}$, a planting area span of $10 \mathrm{~m}$, and a length of $86 \mathrm{~m}$. The back wall is built of soil, where the section shape is trapezoidal. The bottom thickness is $6.5 \mathrm{~m}$, and the top thickness is $1.5 \mathrm{~m}$. Based on the interior floor, the wall is calculated to be $4.0 \mathrm{~m}$ tall, and the ridge is at a height of $4.8 \mathrm{~m}$. The roof was covered with a layer of plastic film for thermal insulation the day before the experiment and also a blanket on the previous night.

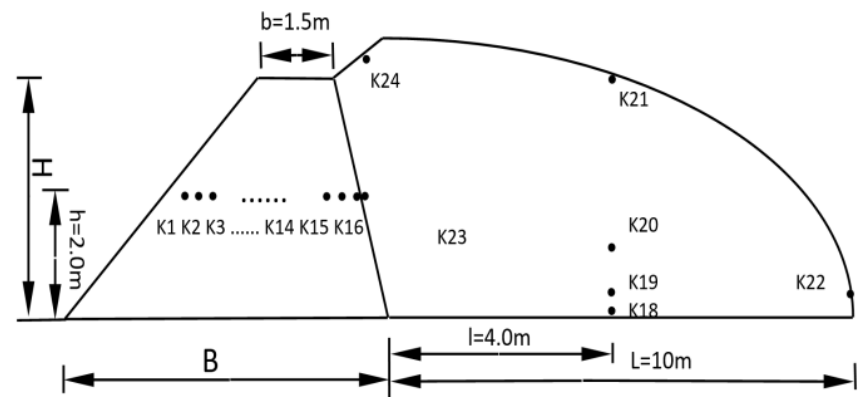

Figure 1. Greenhouse section map and layout of temperature measuring points

Temperature sensors were placed in the walls at 16 points (K1, K2, K3 ... K16) from outside to inside, 2.0m above the ground. Measured from the outside, K1, K2, K3 ... K16 was located at a horizontal depth of $0.25 \mathrm{~m}, 0.5 \mathrm{~m}, 0.75 \mathrm{~m}, \ldots .$. , $3.75 \mathrm{~m}$ and $4.0 \mathrm{~m}$, with the spacing being $0.25 \mathrm{~m}$. All the sensors 
in the greenhouse were arranged at $1 / 2$ of the longitudinal length of the greenhouse. K18 was located in the indoor ground, and K19, K20, K21, K22, K23 and K24 are respectively $0.5 \mathrm{~m}, 1.5 \mathrm{~m}, 4.0 \mathrm{~m}, 0.5 \mathrm{~m}, 2.0 \mathrm{~m}$ and $4.2 \mathrm{~m}$ above the ground. The greenhouse section model and the layout of the temperature measuring points are shown in Fig.1. The temperature experiment was conducted using the Toprie TP9000 multi-channel temperature recorder, as shown in Fig. 2. The sampling period was 35 days (from December 17, 2017 to January 20, 2018), and the data sampling interval was $20 \mathrm{~min}$. The interior of the greenhouse is shown in Fig.3.

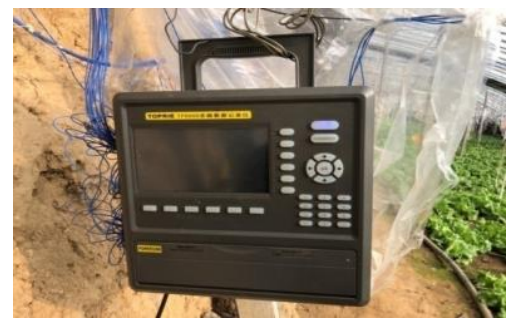

Figure 2. Experimental instrument

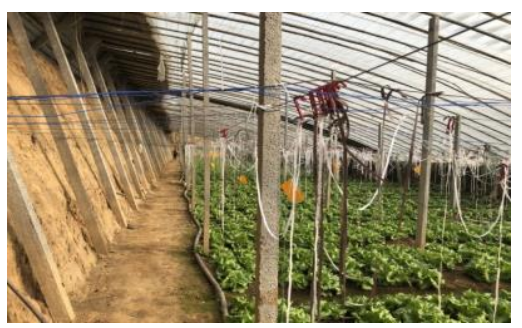

Figure 3. Interior of the greenhouse

\subsection{Experimental results}

Through the temperature field experiment in the greenhouse, the temperature distributions of different measuring points in the wall on the coldest day (January 6, 2018) and the hottest day (December 20, 2017) were obtained, as shown in Fig.4. The daily average temperature distributions of different measuring points in the wall are shown in Fig.5.

As can be seen from Fig.4-a, on the coldest day, the temperature on the outer side of the wall (at measuring point $\mathrm{K} 1$ ) ranged between $0.4{ }^{\circ} \mathrm{C}$ to $1.9^{\circ} \mathrm{C}$, and that on the inner side of the wall (at measuring point $\mathrm{K} 16$ ) ranged between $14.5{ }^{\circ} \mathrm{C}$ to $15.9^{\circ} \mathrm{C}$. In Fig.4-b, on the hottest day, the temperature on the outer side of the wall (at measuring point $\mathrm{K} 1$ ) ranged between $0.5{ }^{\circ} \mathrm{C}$ to $2{ }^{\circ} \mathrm{C}$; and that on the inner side ranged between, $15^{\circ} \mathrm{C}$ to $19.8^{\circ} \mathrm{C}$. The temperatures on December 20 were higher than those on January 6 , because on the hottest experiment day, the solar radiation was strong and the inner side of the wall received more heat. The outer side of the wall, due to the lack of solar radiation, experienced less heat exchange and naturally had small temperature differences. As can be seen from Fig.5, the overall temperature inside the wall body (from outside to inside) showed an upward trend, with the highest temperature in the wall being at the depth of $0.75 \mathrm{~m}$ (at measuring point K14). This was because on the coldest day, with the solar radiation being relatively weak, cold air intruded $\mathrm{K} 15$ and K16 in the wall, leading to continuous release of the heat. From Fig.5-b, it can be seen that K16 in the wall had the highest daily average temperature, because the solar radiation was strong on December 20, making the wall absorb more heat and leading to high temperatures at K15 and K16.

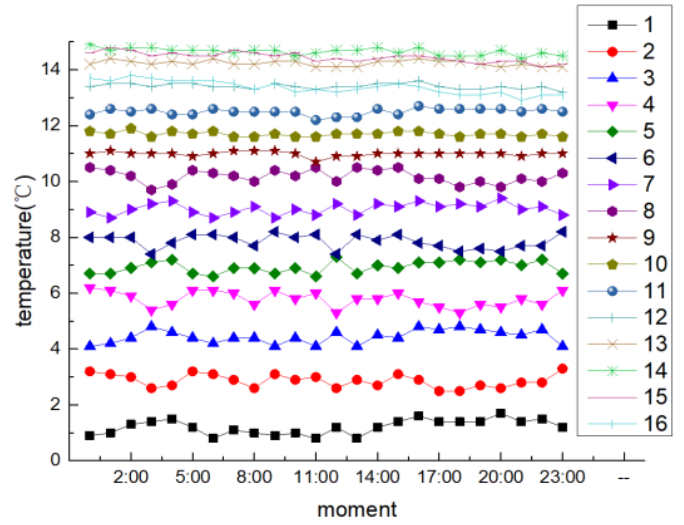

Figure 4-a. Wall body temperature trend chart on January 6

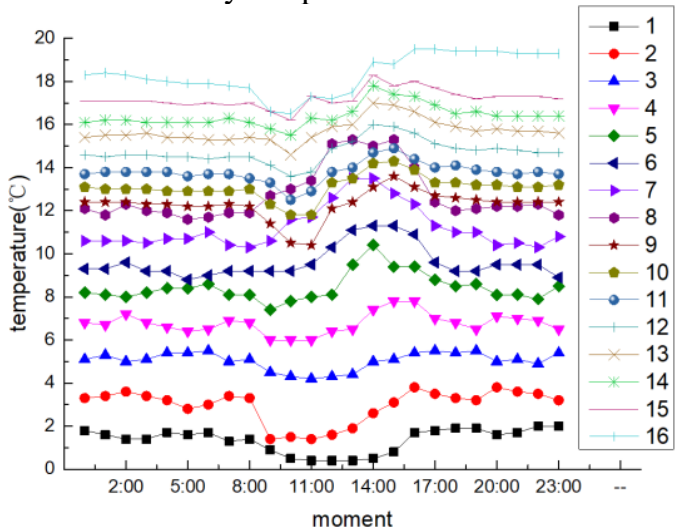

Figure 4-b. Wall body temperature trend chart on December 20

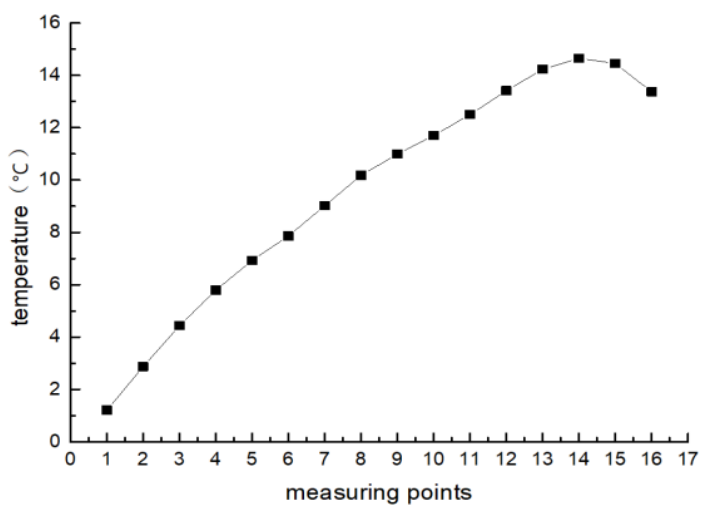

Figure 5-a. Daily average temperature trend chart of all measuring points on January 6

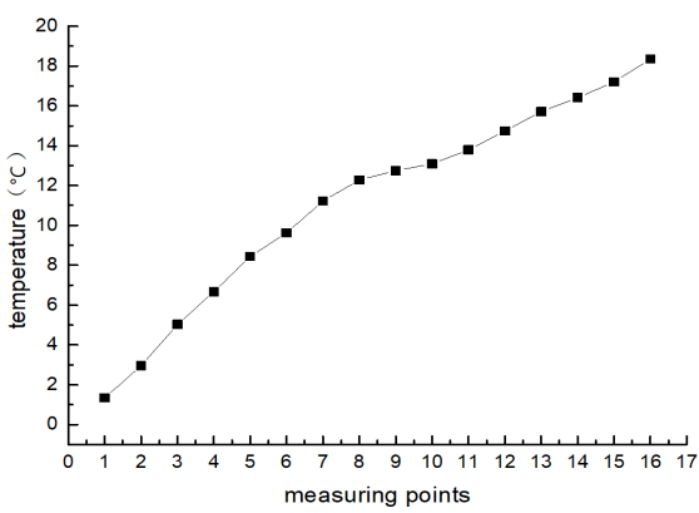

Figure 5-b. Daily average temperature trend chart of all measuring points on December 2 


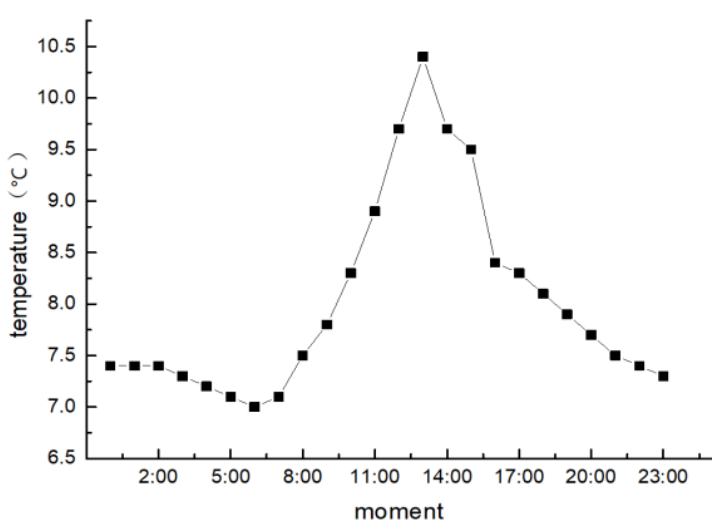

Figure 6-a. Temperature trend chart of K19 on January 6

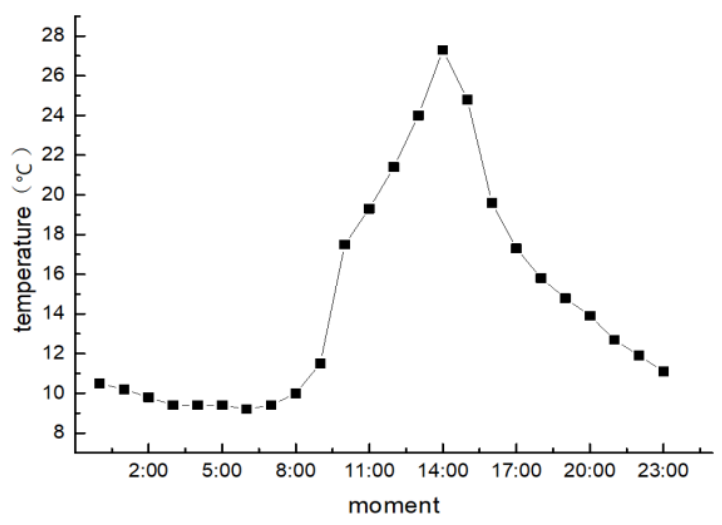

Figure 6-b. Temperature trend chart of K19 on December 20

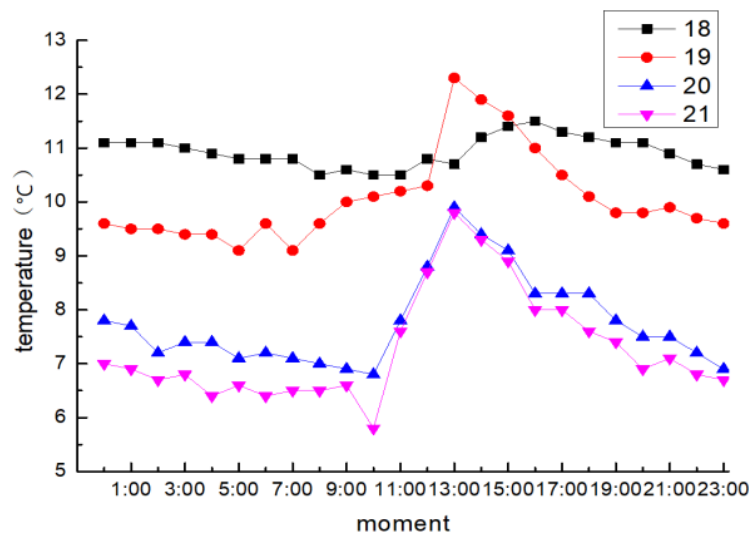

Figure 7-a. Temperature trend of different heights in greenhouse on January 6

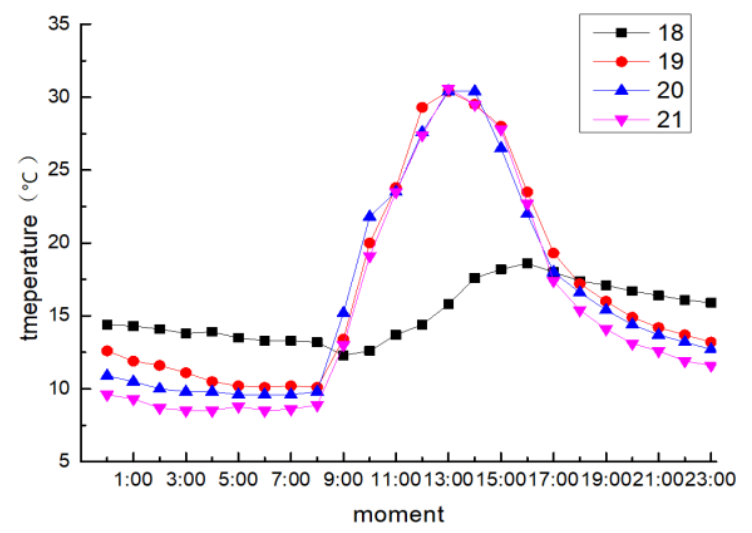

Figure 7-b. temperature trend of different heights in greenhouse December 20
On the coldest day (January 6) and the hottest day (December 20) in the greenhouse, the temperature trends of the measuring point at a depth of $0.5 \mathrm{~m}$ (K19) are shown in Fig.6, and the temperature trends of the measuring points at different heights (K18, K19, K20 and K21) in the greenhouse are shown in Fig.7.

According to the measured temperature data, it is concluded that the minimum temperature in the greenhouse in one day usually appears between 6:00 and 7:00. The lowest temperature was $6.7{ }^{\circ} \mathrm{C}$ on January 6 and $9{ }^{\circ} \mathrm{C}$ on December 20. The reason for this is that the coldest time in the winter of North China is before sunrise, and the greenhouse wall, after a night of exothermic activity, contained very little heat, and in addition, there was still no solar radiation at this moment. Between 7:00 to 8:00, the insulation layer was uncovered, and the greenhouse began to receive solar radiation, causing the temperature to rise from 8:00. Between 8:00 and 14:00, due to the increasing solar radiation intensity, the indoor temperature increased rapidly, and reached the maximum at 14:00. The maximum temperature was $10.4^{\circ} \mathrm{C}$ on January 6 and $27.5^{\circ} \mathrm{C}$ on December 20. At 14:00, the solar radiation intensity was the strongest of the whole day, and the greenhouse was directly exposed to the sunlight, so the temperature reached the peak at this moment. After 14:00, the outdoor temperature began to decline, and with the solar radiation intensity gradually weakening, the temperature in the greenhouse also decreased. On December 20, the external temperature was higher and the solar radiation stronger, while on January 6 , the temperature became lower and the solar radiation weaker, so the temperature at K19 on December 20 was higher than that on January 6 , indicating that the temperature in the greenhouse is affected by the external temperature. It can be concluded from Fig.7 that the temperature of the ground (K18) in the greenhouse is more stable, because the soil has thermal stability, and when the ambient temperature is low, the ground temperature can still be maintained at a higher level through the exothermic activity within the soil.

\section{NUMERICAL SIMULATION OF THE TEMPERATURE FIELD}

\subsection{Numerical modelling of the temperature field}

Chen [8] concluded in his paper that in order to ensure that the back wall can be fully exposed to the sunlight and improve its heat storage, the elevation angle of the back roof should be at least greater than the incidence angle of the sunlight at noon in the local winter solstice, which is generally maintained between the $35^{\circ} \sim 45^{\circ}$. Therefore, in this study, the elevation angle of the back roof should be $45^{\circ}$. The greenhouse used in this experiment is far larger in the longitudinal direction than in the span direction, and the heat release from the east-west gable wall took up only $4.7 \%$ of the total release from the greenhouse enclosure structure, so the influence of the eastwest gable wall on the temperature was ignored in the simulation. In addition, the influence of the physiological activity of the crops on the temperature is ignored, too [9].

Considering the required temperature for normal plant growth and by reference to the above literatures, this paper uses Ansys CFD (Computational Fluid Dynamics) to perform three-dimensional numerical analysis of the temperature field in the solar greenhouse, and establishes a three-dimensional mesh model for the greenhouse structure, as shown in Fig. 8. 


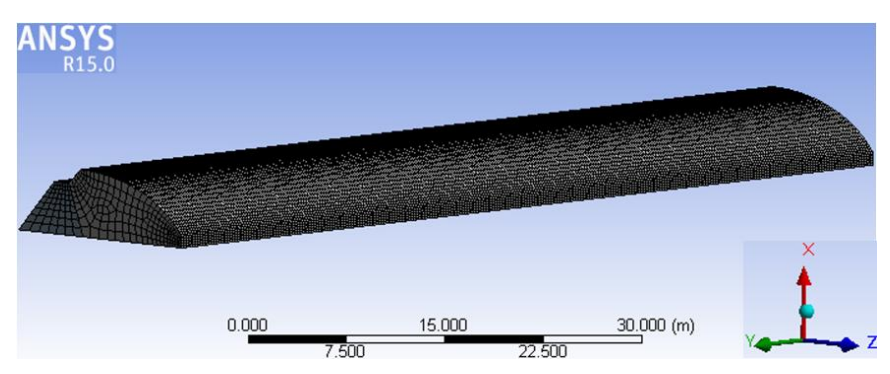

Figure 8. 3D grid model of greenhouse

Because of the temperature differences in the enclosure structure, the solar greenhouse gas will form natural convection exchange. The buoyancy caused by the temperature difference is treated under the Boussinesq hypothesis. On the basis of the finite volume method, the standard k- $\varepsilon$ turbulence model, energy balance equations, DO (discrete coordinate radiation) model, SIMPLE algorithm and segregated solver for low frequency domain are widely used in the engineering field to solve the transient calculation. The thermal analysis of the solar greenhouse wall follows the first law of thermodynamics, that is, the conservation of energy in a closed system (no mass inflow or outflow), expressed in equation (1):

$Q_{S^{-}} W=\Delta U+\triangle K E+\triangle P E$

where: $Q_{S}$ is the heat transferred, in $J$;

$W$ is the work, in $J$;

$\Delta U$ is the internal energy of the system, in $J$; $\triangle K E$ is the kinetic energy of the system, in $J$;

$\triangle P E$ is the potential energy of the system, in $J$.

For most engineering heat transfer problems: $\triangle K E=\triangle P E=0$; Usually it is deemed that there is no work, i.e. $W=0$, so $Q_{S}=\Delta U$; for steady-state heat transfer analysis: $Q_{S}=\Delta U=0$. The heat that flows into the system equals the heat flowing out.

\subsection{Boundary conditions}

According to the measured temperature data in the field, the variation of outdoor temperature was similar to that of the $24 \mathrm{~h}$ harmonic wave. Using the software MATLAB to fit the data of the outdoor temperature by Fourier, we have the formula of outdoor air temperature variation as follows:

$T_{0}=2728-2416^{*} \cos 0.2914 \tau+6.65 * \sin 0.2914 \tau$ $0.0422 * \cos 0.583 \tau+2392 * \sin 0.593 \tau$

where: $\tau$ represents the time of the day.

Generally the effective air temperature is used as the external radiation temperature, to reflect the impact of the air radiation background on the heat transfer. The calculation formula for the external radiation temperature is as follows:

$T_{S K Y}=0.0552 T 1.50$

According to the literature [10-13], the convective heat transfer coefficient of the inner surface of the enclosure structure and gas is selected. The physical parameters of the enclosure structure in the model are shown in Table 1.

Table 1. Material and physical parameters of the enclosure structure

\begin{tabular}{ccccccc}
\hline Structural material & $\begin{array}{c}\text { Density } \\
\left(\mathrm{kg} \cdot \mathrm{m}^{-3}\right)\end{array}$ & $\begin{array}{c}\text { Specific heat capacity } \\
\left(\mathrm{J} \cdot \mathrm{kg}^{-1} \cdot \mathrm{K}^{-1}\right)\end{array}$ & $\begin{array}{c}\text { Thermal conductivity } \\
\left(\mathrm{W} \cdot \mathrm{m}^{-1} \cdot \mathrm{K}^{-1}\right)\end{array}$ & $\begin{array}{c}\text { Heat transfer coefficient } \\
\left(\mathrm{W} \cdot \mathrm{m}^{-2} \cdot \mathrm{K}^{-1}\right)\end{array}$ & $\begin{array}{c}\text { Absorptivity } \\
\text { Radiant } \\
\text { rate }\end{array}$ \\
\hline Soil wall Body & 1600 & 1050 & 1.432 & 9.44 & 0.8 & 0.37 \\
Soil ground & 1400 & 840 & 1.518 & 8.51 & -- & 1.0 \\
Insulation quilt (Felt) & 400 & 820 & 0.08 & 0.8 & 0.8 & 0.95 \\
\hline
\end{tabular}

\subsection{Comparison between simulation and experimental results}

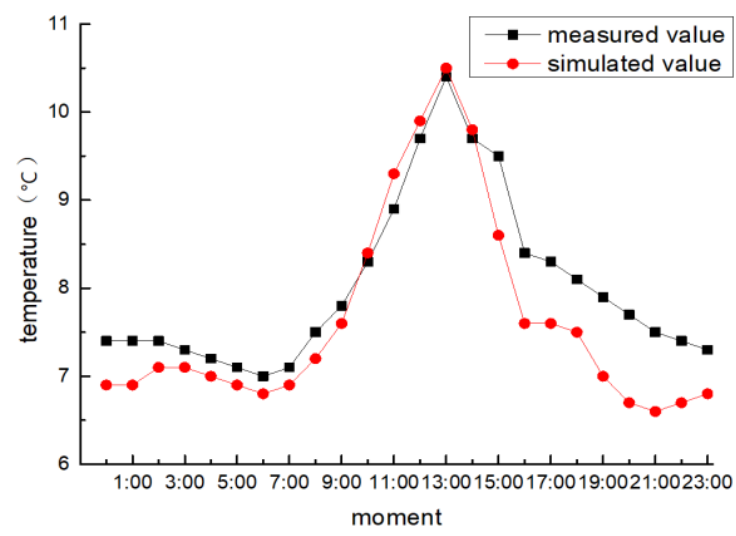

Figure 9. Comparison between the simulated and the measured values

This paper then establishes a CFD model of the greenhouse with the experimental size and compares the simulated temperature and the actual one at measuring point K19 on January 6, as shown in Fig.9. As can be seen, the simulated results are in good agreement with the measured values, which shows that the theoretical three-dimensional space CFD model of solar greenhouse is correct and reasonable. The causes of the error include the physiological activity of plants and the difference between the model and the actual situation.

\subsection{Analysis of numerical simulation results}

3.4.1 Numerical analysis of the temperature field in the greenhouse with different wall thicknesses

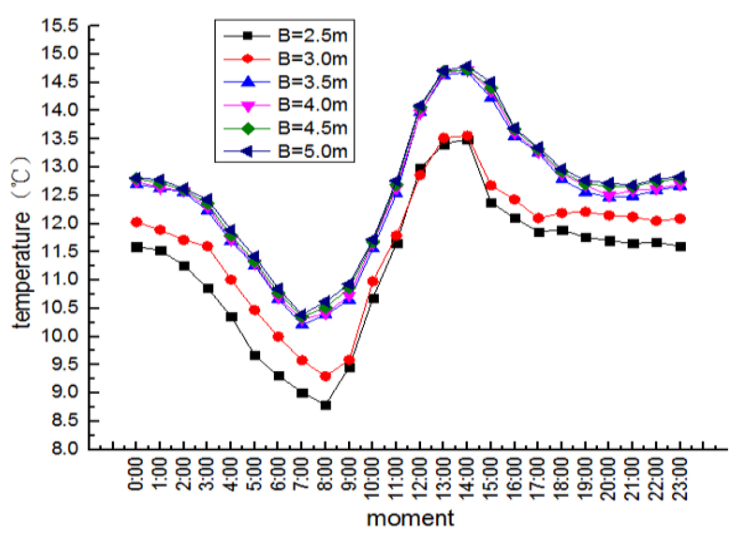

Figure 10. Temperature variation on the surface 
The original greenhouse wall size (an upper thickness of $1.5 \mathrm{~m}$ and a lower thickness of $6.5 \mathrm{~m}$ ) is too large. Although such a wall can achieve thermal storage, it causes a serious waste of land resources and affects the production efficiency. With the aid of the CFD numerical analysis software, this paper numerically analyzes the walls with different bottom thicknesses $(\mathrm{B}=5.0 \mathrm{~m}, \mathrm{~B}=4.5 \mathrm{~m}, \mathrm{~B}=4.0 \mathrm{~m}, \mathrm{~B}=3.5 \mathrm{~m}, \mathrm{~B}=3.0 \mathrm{~m}$ and $B=2.5 \mathrm{~m}$ ) when the wall height is $\mathrm{H}=4.0 \mathrm{~m}$ and the upper thickness is $b=1.5 \mathrm{~m}$, and obtains the surface diurnal temperature changes in the half span of the greenhouse, as shown in Fig.10.

As can be seen from Fig. 10, when $\mathrm{B}=2.5 \mathrm{~m}$, the insulation effect is the worst. At 8:00, the temperature is as low as $8.8^{\circ} \mathrm{C}$, because the $2.5 \mathrm{~m}$ wall is too thin to accumulate enough heat for the $80 \mathrm{~m}$-long greenhouse. When $\mathrm{B}=3.0 \mathrm{~m}$, the wall still cannot achieve a good insulation effect. The minimum temperature in the greenhouse is around sunrise time (7:00 8:00). When $\mathrm{B}=5.0 \mathrm{~m}$, the minimum temperature is $10.39{ }^{\circ} \mathrm{C}$; when $\mathrm{B}=4.5 \mathrm{~m}$, it is $10.35{ }^{\circ} \mathrm{C}$; when $\mathrm{B}=4.0$, it is $10.31^{\circ} \mathrm{C}$; and when $\mathrm{B}=3.5 \mathrm{~m}$, it is $10.21{ }^{\circ} \mathrm{C}$. The lowest temperature is $9.08^{\circ} \mathrm{C}$ and $9.01{ }^{\circ} \mathrm{C}$, when the bottom thickness is $3.0 \mathrm{~m}$ and $2.5 \mathrm{~m}$ respectively. It can be seen that when the wall thickness increases, the insulation effect gets better, but thisupward trend also becomes slower - the lowest temperature when $\mathrm{B}=5.0$ is only $0.18^{\circ} \mathrm{C}$ higher than that when $\mathrm{B}=3.5 \mathrm{~m}$. At this point, the temperature changes basically consistently with the external temperature. From 8:00 9:00 when theinsulation layer is uncovered, the temperature begins to rise, and between 13:00 14:00, the temperature becomes higher. After the sunset, the roof cover is insulated before the greenhouse, and the wall began to release heat, so the temperature here is always maintained at $10^{\circ} \mathrm{C}$ or above.

By CFD numerical analysis of different wall sizes, the diurnal temperature variation $1 \mathrm{~m}$ above the surface of the greenhouse is obtained as shown in Fig. 11.

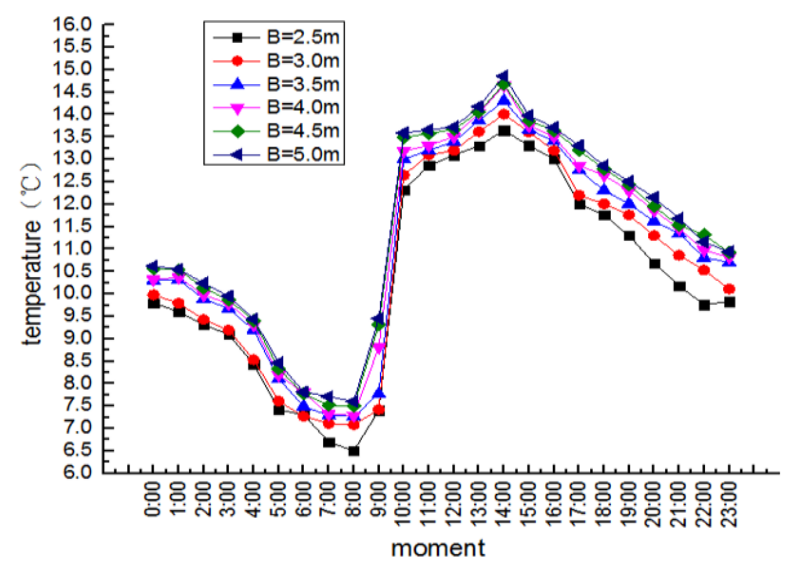

Figure 11. Temperature variation $1 \mathrm{~m}$ above the surface

As can be seen from Fig.11, the overall temperature $1 \mathrm{~m}$ from the surface is lower than the temperature of the surface, because of the surface heat, and the slow air flow on the surface. When $B=2.5 \mathrm{~m}$, the thermal insulation effect is the worst, wth the lowest temperature here being as low as $6.5^{\circ} \mathrm{C}$. When $\mathrm{B}=3.5 \mathrm{~m}, \mathrm{~B}=4.0 \mathrm{~m}, \mathrm{~B}=4.5 \mathrm{~m}$ and $\mathrm{B}=5.0 \mathrm{~m}$, the insulation effects of the wall differ little and the temperatures can all be maintained at a high level, which are $14.86^{\circ} \mathrm{C}, 14.68^{\circ} \mathrm{C}, 14.65^{\circ} \mathrm{C}$ and $14.31{ }^{\circ} \mathrm{C}$, respectively. The daily temperature change in this part is in line with the actual situation

Through the CFD numerical analysis of different wall sizes, the diurnal temperature variation $2 \mathrm{~m}$ above the surface of the greenhouse is obtained, as shown in Fig.12.

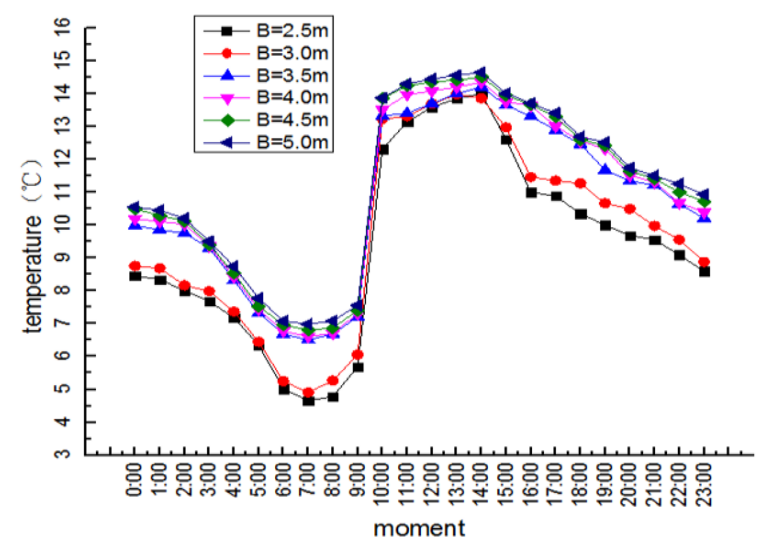

Figure 12. Temperature variation $2 \mathrm{~m}$ above the surface

As can be seen from Fig.12, the overall temperature $2 \mathrm{~m}$ above the surface is lower than that $1 \mathrm{~m}$ above the surface, because it is far from the surface heat source, and close to the open air. Although the insulation can achieve heat preservation to some extent, the thermal conductivity of the insulation is not 0 , so there is still some loss of heat. When $\mathrm{B}=2.5 \mathrm{~m}$, as the wall is too thin to accumulate enough heat, the heat preservation effect at this time is still the worst. When $b=3.0 \mathrm{~m}$, the lowest temperature here is $4.91{ }^{\circ} \mathrm{C}$, lower than those in other wall models (except in the model where $B=2.5 \mathrm{~m}$ ). When $\mathrm{B}=3.5 \mathrm{~m}, \mathrm{~B}=4.0 \mathrm{~m}, \mathrm{~B}=4.5 \mathrm{~m}$ and $\mathrm{B}=5.0 \mathrm{~m}$, the heat preservation effect is good, with the maximum temperature being $14.66^{\circ} \mathrm{C}$ when $\mathrm{B}=5.0 \mathrm{~m}$. The daily temperature change is basically in line with the actual situation.

Through the CFD numerical analysis of different wall sizes, the diurnal temperature variation $3 \mathrm{~m}$ above the surface of the greenhouse is obtained, as shown in Fig. 13.

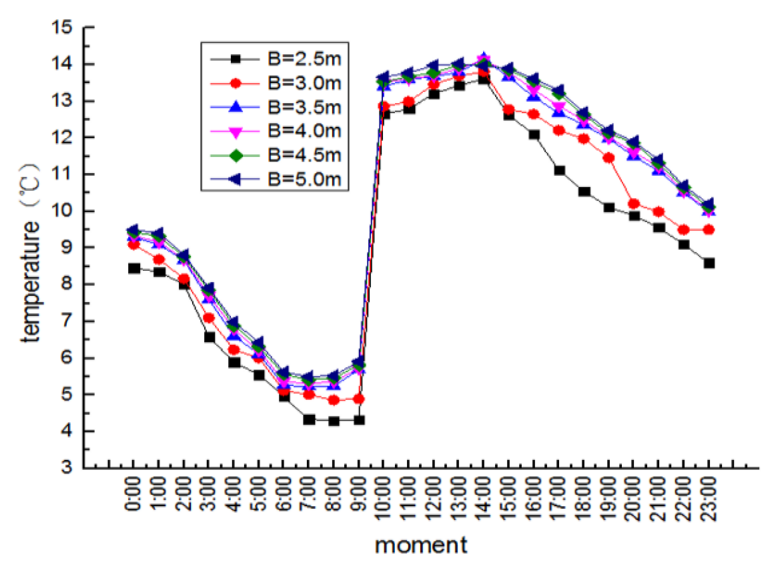

Figure 13. Temperature variation $3 \mathrm{~m}$ above the surface

As can be seen from Fig.13, the temperature is affected by the external temperature - the temperature in the greenhouse $3 \mathrm{~m}$ from the surface of the ground is below those at other heights. When $\mathrm{B}=2.5 \mathrm{~m}$, the temperature is $4.29^{\circ} \mathrm{C}$, with the worse heat preservation effect; when $\mathrm{B}=3.0 \mathrm{~m}$, temperature is the second lowest. The insulation effects of the walls with the other sizes do not differ much. As it is far from the planting area, the low temperature here has little effect on the whole greenhouse.

Through the CFD numerical analysis of different wall sizes, the lowest temperatures of the walls with different thicknesses and heights are listed in the Table 2. 
Table 2. Minimum temperatures of different models $\left({ }^{\circ} \mathrm{C}\right)$

\begin{tabular}{c|cccccc}
\hline $\begin{array}{c}\text { Bottom } \\
\text { thickness }\end{array}$ & 2.5 & 3.0 & 3.5 & 4.0 & 4.5 & 5.0 \\
$\begin{array}{c}\text { Height from } \\
\text { ground }\end{array}$ & & & & & & \\
\hline 0 & 8.79 & 9.08 & 10.21 & 10.31 & 10.35 & 10.39 \\
1 & 6.5 & 7.08 & 7.27 & 7.29 & 7.5 & 7.6 \\
2 & 4.66 & 4.91 & 6.51 & 6.61 & 6.81 & 6.99 \\
3 & 4.29 & 4.86 & 5.23 & 5.3 & 5.41 & 5.5 \\
\hline
\end{tabular}

It can be concluded from Table 2 that the minimum temperatures of the various models decrease with the increasing elevation from the surface. This is because when the wall experiences exothermic activities at night, the surface soil also releases heat, and the greater the distance from the outdoor environment, the more active the heat exchange with the outside. Since the crops grown in the greenhouse are not very tall, the minimum temperature at a height of $2 \mathrm{~m}$ and $3 \mathrm{~m}$ above the surface has little effect on the crops. It can be seen from the table that the minimum temperature on the surface is $10.39{ }^{\circ} \mathrm{C}$ when $\mathrm{B}=5.0 \mathrm{~m}$ and it is $10.21^{\circ} \mathrm{C}$ when $\mathrm{B}=3.5 \mathrm{~m}$, only $0.18^{\circ} \mathrm{C}$ lower that the former, which satisfies the requirement for the growth of most crop roots. At a height of $1 \mathrm{~m}$ from the surface, the minimum temperature of each model (except when $\mathrm{B}=2.5 \mathrm{~m}$ ) is above $7{ }^{\circ} \mathrm{C}$, which also satisfies the requirement for the growth of most crops.

Through the CFD numerical analysis, it can be concluded that when $\mathrm{B}=3.5 \mathrm{~m}, \mathrm{~B}=4.0 \mathrm{~m}, \mathrm{~B}=4.5 \mathrm{~m}$ and $\mathrm{B}=5.0 \mathrm{~m}$, the heat preservation effects of the greenhouse model are basically the same, so it is obvious that reducing the bottom thickness of the wall does not affect the insulation effect, and that at the same time it can save land resources and improve agricultural production efficiency.

2.4.2 Numerical analysis of the temperature field in the greenhouse with different wall heights

An excessively large height of the greenhouse back wall will directly affect the land utilization rate. In the CFD numerical analysis, the upper thickness $b=1.5 \mathrm{~m}$, the bottom thickness $b=3.5 \mathrm{~m}$ and the wall heights are respectively $\mathrm{H}=2.5 \mathrm{~m}, \mathrm{H}=3.0 \mathrm{~m}, \mathrm{H}=3.5 \mathrm{~m}, \mathrm{H}=4.0 \mathrm{~m}, \mathrm{H}=4.0 \mathrm{~m}$ and $\mathrm{H}=4.5 \mathrm{~m}$. The surface diurnal temperature changes in the half span of the greenhouse are obtained as shown in Fig. 14.

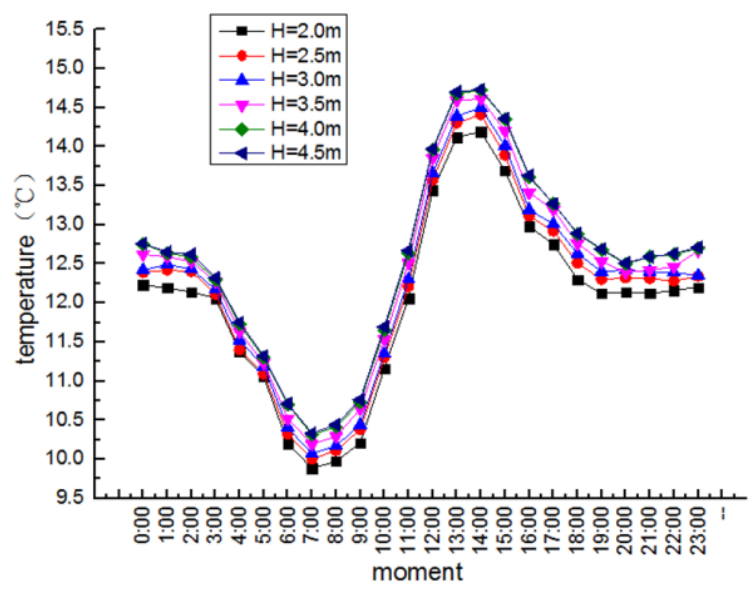

Figure 14. Temperature variation at the ground level

As can be seen from Fig.14, when $\mathrm{H}=2.0 \mathrm{~m}$, the heat preservation effect is poor, but the minimum temperature is still $9.88^{\circ} \mathrm{C}$, because the wall has enough thickness to accumulate some heat and maintain the temperature inside the greenhouse at a high level. When $\mathrm{H}=4.5 \mathrm{~m}$, the minimum temperature in the greenhouse is $10.33^{\circ} \mathrm{C}$, only $0.45^{\circ} \mathrm{C}$ higher than that at $\mathrm{H}=2.0 \mathrm{~m}$. The minimum temperatures of the other four models are $10{ }^{\circ} \mathrm{C}, 10.07{ }^{\circ} \mathrm{C}, 10.19{ }^{\circ} \mathrm{C}$ and $10.31{ }^{\circ} \mathrm{C}$, respectively. With the increase in the wall height, the minimum temperature also increases accordingly, but the upward trend is relatively flatter, because the wall itself has a certain thickness $(B=3.5 \mathrm{~m})$ to accumulate heat. After the greenhouse is covered with the insulation layer, the wall body can release enough heat to maintain the temperature inside the greenhouse. The highest temperature here is between 13:00 14:00, which is in line with the actual situation.

Through the CFD numerical analysis of different wall sizes, the diurnal temperature variation at a height of $1 \mathrm{~m}$ above the surface in the half span of the greenhouse is obtained, as shown in Fig. 15.

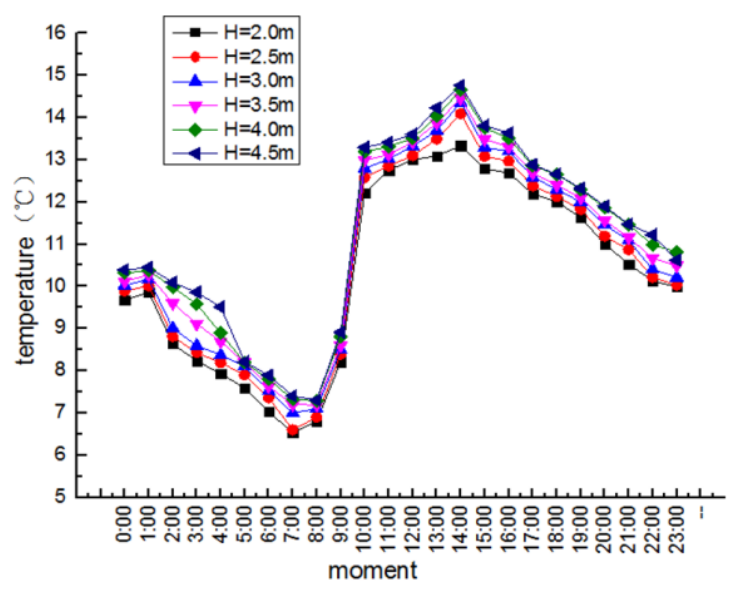

Figure 15. Temperature variation $1 \mathrm{~m}$ above the surface

As can be seen from Fig.15, the minimum temperatures of the wall models are $6.53{ }^{\circ} \mathrm{C}, 6.6^{\circ} \mathrm{C}, 7^{\circ} \mathrm{C}, 7.19^{\circ} \mathrm{C}, 7.29^{\circ} \mathrm{C}$ and $7.3{ }^{\circ} \mathrm{C}$, respectively, and the minimum temperature increases with the increasing height of the wall body. The minimum temperatures at $\mathrm{H}=4.5 \mathrm{~m}$ and $\mathrm{H}=4.0 \mathrm{~m}$ have a difference of only $0.01{ }^{\circ} \mathrm{C}$, indicating that they are almost equal. This shows an excessively great wall height does not improve the insulation effect of the greenhouse too much. With the wall size increases, the temperature inside the greenhouse rises more slowly. After the insulation is uncovered at 9:00, the temperature begins to rise, and at 14:00, it reaches the peak of the day. The daily temperature changes are in line with the actual situation.

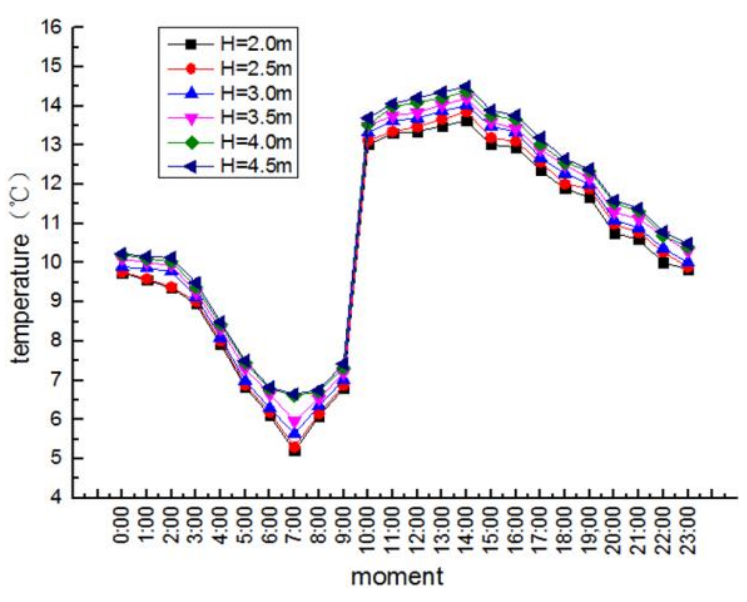

Figure 16. Temperature variation $2 \mathrm{~m}$ above the surface 
Through the CFD numerical analysis of different wall sizes, the diurnal temperature variation at a height of $2 \mathrm{~m}$ above the ground in the half span of the greenhouse is obtained, as shown in Fig. 16.

As can be seen from Fig.16, the minimum temperatures of the wall models are $5.2{ }^{\circ} \mathrm{C}, 5.3{ }^{\circ} \mathrm{C}, 5.63{ }^{\circ} \mathrm{C}, 5.96{ }^{\circ} \mathrm{C}, 6.61{ }^{\circ} \mathrm{C}$ and $6.65^{\circ} \mathrm{C}$. With the increase of the wall height, the minimum temperature also increases, but being far away from the area of crops, the low temperature has little effect on their growth. After the insulation is uncovered at 9:00, the temperature begins to rise, and at 14:00, it reaches the peak of the day. The daily temperature changes are in line with the actual situation.

Through the CFD numerical analysis of different wall sizes, the diurnal temperature variation at a height of $3 \mathrm{~m}$ above the ground in the half span of the greenhouse is obtained, as shown in Fig. 17.

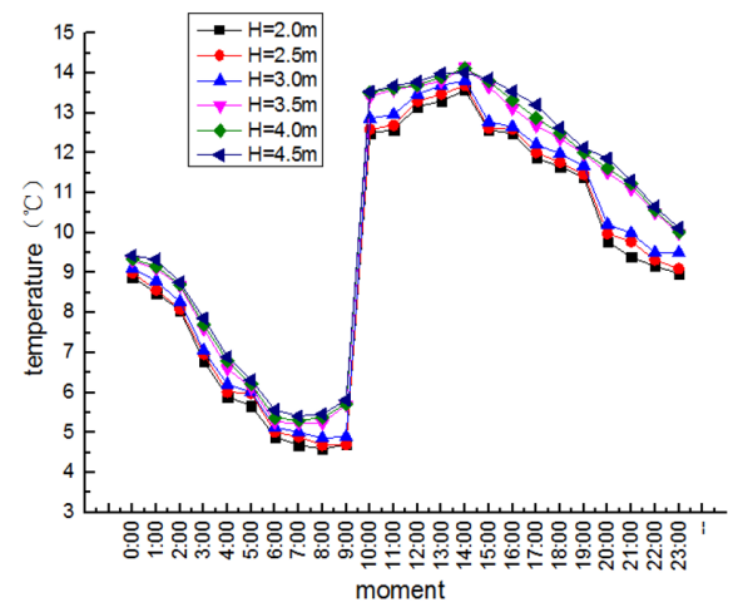

Figure 17. Temperature variation $3 \mathrm{~m}$ above the surface

As can be seen from Fig.17, the position is far from the ground heat source and close to the canopy, so the temperature at night is lower, which is $4.59{ }^{\circ} \mathrm{C}, 4.68{ }^{\circ} \mathrm{C}, 4.86{ }^{\circ} \mathrm{C}, 5.23{ }^{\circ} \mathrm{C}$, $5.3{ }^{\circ} \mathrm{C}$ and $5.41{ }^{\circ} \mathrm{C}$, respectively, but being far from the crops, the low temperature has little effect on their growth.

Through the CFD numerical analysis of different wall sizes, the minimum temperatures of the walls with different heights at different heights above the ground is obtained, as shown in Table 3.

Table 3. Minimum temperatures of different models $\left({ }^{\circ} \mathrm{C}\right)$

\begin{tabular}{c|cccccc}
\hline $\begin{array}{l}\text { Height }(\mathrm{m}) \\
\begin{array}{l}\text { Height frem } \\
\text { ground }\end{array}\end{array}$ & 2.0 & 2.5 & 3.0 & 3.5 & 4.0 & 4.5 \\
\hline 0 & 9.88 & 10.00 & 10.07 & 10.19 & 10.31 & 10.33 \\
1 & 6.53 & 6.60 & 7.00 & 7.19 & 7.29 & 7.30 \\
2 & 5.20 & 5.30 & 5.63 & 5.96 & 6.61 & 6.65 \\
3 & 4.59 & 4.68 & 4.86 & 5.23 & 5.30 & 5.41 \\
\hline
\end{tabular}

As can be found in Table 3, the minimum temperatures of the greenhouse models with different wall sizes decrease with the increasing elevation from the ground. This is because when the wall experiences exothermic activities at night, the surface soil also releases heat, and the greater the distance from the outdoor environment, the more active the heat exchange with the outside. This is consistent with the previous numerical simulation results. Since the crops grown in the greenhouse are not very tall, the minimum temperature at a height of $2 \mathrm{~m}$ and $3 \mathrm{~m}$ above the surface has little effect on the crops. It can be seen from the table that the minimum temperature of the ground is $9.88{ }^{\circ} \mathrm{C}$ when $\mathrm{H}=2.0 \mathrm{~m}$. Though the temperature is the lowest for all models, it still can satisfy the requirement for the growth of most crop roots. When $\mathrm{H}=4.5 \mathrm{~m}$, the minimum temperature of the ground is $10.33^{\circ} \mathrm{C}$, only $0.45^{\circ} \mathrm{C}$ higher than that at $\mathrm{H}=2.0 \mathrm{~m}$, which is not obvious. This temperature range can meet the requirement for the growth of most crops.

Through the CFD numerical analysis, it can be concluded that the heat preservation effects of the greenhouse models with different wall heights are not very different, so it is obvious that reducing the height of the wall does not affect the insulation effect much, and at the same time it can save land resources and improve agricultural production efficiency.

\section{CONCLUSION}

(1) Through the greenhouse temperature experiment, it can be concluded that the inner wall temperature of the greenhouse is affected by the external temperature. When the solar radiation maintains a certain intensity, the soil wall can absorb the heat, and keep the wall temperature at a high level.

(2) Based on the research data, it can be concluded that the greenhouse temperature near the canopy is low, due to the heat exchange with the outside, and away from the ground and wall heat sources. When the height of the back wall is reduced, the insulation effect is better than the original size $(4 \mathrm{~m})$, because with the decreasing height of the greenhouse ridge, the heat dissipation rate slows down, making the overall temperature in the greenhouse higher.

(3) When the wall thickness is increased to a certain extent, continue to increase the thickness will not increase the indoor temperature greatly, but will make more land waste. According to the experiment and the CFD theoretical analysis, it is suggested that the optimal size of the back wall in a solar greenhouse be as follows: $\mathrm{H}=2.5 \mathrm{~m}$ (height), $\mathrm{B}=3.5 \mathrm{~m}$ (bottom thickness) and $b=1.5 \mathrm{~m}$ (upper thickness).

\section{ACKNOWLEDGEMENT}

This paper was supported by Hebei Province key research and development plan project (18227209D); Science and Technology research project of Hebei Province University (ZD2018209).

\section{REFERENCES}

[1] Li M, Zhou CJ, Wei XM. (2015). Thickness determination of heat storage layer of wall in solar greenhouse. Transactions of the Chinese Society of Agricultural Engineering 31(2): 177-183. https://doi.org/10.3969/j.issn.1002-6819.2015.02.025

[2] Peng DL, Zhang Y, Fang H, Yang QC, Wei LL. (2014). MATLAB simulation of one-dimensional heat transfer and heat flux analysis of north wall in Chinese solar greenhouse. Journal of China Agricultural University 19(5): 174-179. https://doi.org/10.11841/j.issn.10074333.2014.05.24

[3] He F, Zhou CJ. (2015). Analysis on test of wall temperature distribution and heat flux in solar greenhouse. Northern Horticulture (10): 58-61. https://doi.org/10.11937/bfyy.201510013 
[4] Xu GY, Zhou CJ. (2004). Performance testing and analysis on different insulation walls of sunlight greenhouse. Journal of Huazhong Agricultural University (z2): 62-66. https://doi.org/10.3321/j.issn:1000-2421.2004.z2.015

[5] Yang JJ, Zou ZR, Zhang Z, Wang YB, Zhang ZX, Yan F. (2009). Optimization of earth wall thickness and thermal insulation property of solar greenhouse in Northwest China. Optimization of earth wall thickness and thermal insulation property of solar greenhouse in Northwest China 25(8): 180-185. https://doi.org/10.3969/j.issn.1002-6819.2009.08.033

[6] Tong G, Li B, David M, Yamaguchi T. (2007). Preliminary study on temperature pattern in China solar greenhouse using computational fluid dynamics. Transactions of the Chinese Society of Agricultural Engineering 23(7): 178-185. https://doi.org/10.3969/j.issn.1002-6819.2007.7.035

[7] Zhang LH, Zhang F, Liu S, Xu L. (2010). Threedimensional non-steady-state simulation of sunken cob wall greenhouse indoor temperature field. ACTA Energiae Solaris Sinica (8): 965-971.

[8] Chen RS. (2004). Design essentials of daylighting and heat preservation in solar greenhouse. Xinjiang Agricultural Mechanization (3): 51-53. https://doi.org/10.3969/j.issn.1007-7782.2004.03.037
[9] Li XF, Chen QY. (2004). Effect of gable wall on the heat gain from direct solar radiation in sunlight greenhouse. Transactions of the Chinese Society of Agricultural Engineering 20(5): 241-245.

[10] Li XZ, Hao WX. (2016). Test and analysis of temperature field with greenhouse soil wall in the middle area of Hebei. Journal of Agricultural University of Hebei 39(6): 101-106.

[11] Peyrac C, Lefebvre F, Westphal O, Gornet L. (2016). Comparison of fatigue limits obtained on thermoplastic composites from SN curve \& self-heating method. Revue des Composites et des Materiaux Avances 26(1): 115126.

[12] Camaraza-Medina Y, Khandy NH, Carlson KM, CruzFonticiella OM., García-Morales OF, Reyes-Cabrera D. (2018). Evaluation of condensation heat transfer in aircooled condenser by dominant flow criteria. Mathematical Modelling of Engineering Problems 5(2): 76-82. https://doi.org/10.18280/mmep.050204

[13] Zhang C, Guo Q, Sun J, Liu C. (2018). Comparative analysis for heat transfer performance of heat exchanger single tube model with and without plug-in. Chemical Engineering Transactions 66, 301-306. https://doi.org/10.3303/CET1866051 